\title{
Effect of Helicobacter pylori eradication on reflux esophagitis and GERD symptoms after endoscopic resection of gastric neoplasm: a single-center prospective study
}

Hee Kyong $\mathrm{Na}^{1}$, Jeong Hoon Lee ${ }^{1 *}$, Se Jeong Park', Hee Jung Park', Sun Ok Kim², Ji Yong Ahn', Do Hoon Kim', Kee Wook Jung ${ }^{1}$, Kee Don Choi ${ }^{1}$, Ho June Song ${ }^{1}$, Gin Hyug Lee ${ }^{1}$ and Hwoon-Yong Jung ${ }^{1}$

\begin{abstract}
Background: The association between Helicobacter pylori and reflux esophagitis (RE) remains controversial. This study aimed to prospectively evaluate the effect of $H$. pylori eradication on RE and gastroesophageal reflux (GERD) symptoms in H. pylori-positive patients who underwent endoscopic resection of gastric neoplasm.

Methods: Of the 244 patients enrolled in this study, $173 \mathrm{H}$. pylori-positive patients underwent follow-up at least once. We evaluated the prevalence of RE and GERD symptoms in these patients following H. pylori eradication.

Results: There were 75.7\% (131/173), 78.6\% (125/159), and 78.9\% (105/133) subjects who were successfully eradicated after 6, 12, and 18-24 months, respectively. During the 2-year follow-up period, the eradication of $H$. pylori did not increase the incidence of RE (OR 0.93; 95\% Cl, 0.49-1.77, $p=0.828)$. H. pylori status was also not associated with the development of GERD symptoms (OR 1.12; 95\% Cl, 0.47-2.95, $p=0.721$ ). In the univariate analysis for $\mathrm{RE}$, present smoking history (OR 4.79; $95 \% \mathrm{Cl} 1.98-11.60, p=0.001)$, present alcohol consumption history (OR 2.18; 95\% Cl 1.03-4.63, $p=0.041$ ), and diabetes mellitus (OR 2.44; 95\% Cl 1.02-5.86, $p=0.045$ ) were found to be associated with RE. Multivariate analysis showed that present smoking history (OR 4.54; 95\% Cl 1.84-11.02, $p=0.001$ ) was a significant risk factor for RE.
\end{abstract}

Conclusions: H. pylori eradication did not increase the incidence of RE or GERD symptoms in patients who underwent endoscopic resection of gastric neoplasm.

Keywords: Helicobacter pylori, Eradication, Reflux esophagitis, Gastroesophageal reflux

\footnotetext{
*Correspondence: jhlee.gi@amc.seoul.kr

'Department of Gastroenterology, University of Ulsan College of Medicine,

Asan Medical Center, 88, Olympic-ro 43-gil, Songpa-gu, Seoul 05505, South

Korea

Full list of author information is available at the end of the article
}

(c) The Author(s). 2020 Open Access This article is licensed under a Creative Commons Attribution 4.0 International License, which permits use, sharing, adaptation, distribution and reproduction in any medium or format, as long as you give appropriate credit to the original author(s) and the source, provide a link to the Creative Commons licence, and indicate if changes were made. The images or other third party material in this article are included in the article's Creative Commons licence, unless indicated otherwise in a credit line to the material. If material is not included in the article's Creative Commons licence and your intended use is not permitted by statutory regulation or exceeds the permitted use, you will need to obtain permission directly from the copyright holder. To view a copy of this licence, visit http://creativecommons.org/licenses/by/4.0/ The Creative Commons Public Domain Dedication waiver (http://creativecommons.org/publicdomain/zero/1.0/) applies to the data made available in this article, unless otherwise stated in a credit line to the data. 


\section{Background}

Helicobacter pylori plays a key role in the pathogenesis of various diseases such as peptic ulcers, gastric mucosaassociated tissue lymphoma, and intestinal-type gastric cancer. Since Schutze et al. first mentioned in 1995 that reflux esophagitis (RE) was developed after $H$. pylori eradication [1], numerous studies on the association of H. pylori with RE or gastroesophageal reflux (GERD) symptoms have been reported. Reports have shown that $H$. pylori infection is negatively associated with erosive esophagitis and Barrett's esophagus but not with GERD symptoms [2-5].

Based on the study showing that $H$. pylori eradication significantly lowers the incidence of metachronous lesion in patients who underwent endoscopic resection of early gastric cancer, we evaluated the effect of $H$. pylori eradication on RE and GERD symptoms in a large cohort of patients who underwent endoscopic resection of gastric epithelial neoplasm and had $H$. pylori infection. These patients, who are less likely to lose follow-up, are relatively homogenous. The aim of our study was to evaluate the effect of $H$. pylori eradication on RE and GERD symptoms in a large cohort of patients who underwent endoscopic resection of gastric epithelial neoplasm and had $H$. pylori infection.

\section{Methods}

\section{Patients}

We conducted a single-center prospective study. Enrolled patients were aged 20-70 years who underwent endoscopic resection including endoscopic mucosal resection and endoscopic submucosal dissection of gastric neoplasm at Asan Medical Center, Seoul, Korea, from September 2012 to March 2014. Patients were excluded on the basis of the following criteria: (1) H. pylori-negative, (2) presence of upper gastrointestinal bleeding, (3) presence of esophageal or gastric varices, (4) presence of esophageal or pyloric stenosis, (5) previous history of gastrectomy, (6) history of $H$. pylori eradication, (7) presence of tumor at the gastroesophageal junction or pylorus resulting in outlet obstruction, (8) past or present history of taking $\mathrm{H} 2$ receptor blocker or proton pump inhibitor (PPI) within at least 1 month, (9) alcohol or drug abuse, and (10) being pregnant. Written informed consent was obtained from all participants. The study was conducted according to the guidelines of the Declaration of Helsinki and was approved by the Institutional Review of Board of Asan Medical Center (IRB number: 2014-2-10).

\section{Questionnaires}

Patients who agreed to participate in the study answered questionnaires regarding GERD symptoms initially, at 6 months, and at 12 months after endoscopic resection.
The questionnaire (Supplementary file) which we developed included questions regarding typical reflux symptoms; heartburn and acid regurgitation. If the patients replied yes to the questions, they were provided with further questions regarding the symptom severity that was categorized as mild, moderate, and severe. Body mass index (BMI) and status of alcohol consumption and smoking were recorded.

\section{Endoscopic examinations}

The endoscopist was blinded to the result of the questionnaires. The presence or absence of RE was evaluated initially when the patient underwent endoscopic resection. The severity of RE on EGD was graded in accordance with the Los Angeles classification system [6]. Minor changes in the squamocolumnar junction, such as blurring or hyperemic changes were not considered as RE. Gastroesophageal junction extending more than 2 $\mathrm{cm}$ from the diaphragmatic impingement determined hiatal hernia [7]. Gastric mucosal atrophy was evaluated and the atrophic type was divided into closed and open types according to endoscopicatrophic border. Closedtype atrophic gastritis (antral predominant gastritis) was diagnosed when the atrophic border remained on the lesser curvature of the corpus, whereas open-type atrophic gastritis (pangastritis or corpus predominant gastritis) was diagnosed when the atrophic border no longer existed on the lesser curvature, but extended along the anterior and posterior walls of the stomach [8].

The serum levels of pepsinogens I (PGI) and II (PGII) were evaluated using Pepsinogen I and Pepsinogen II EIA TEST kits (BiohitOyj, Helsinki, Finland). When PGI levels were $<25 \mu \mathrm{g} / \mathrm{L}$ and PGI to PGII ratio was $<3$, serological atrophy was defined to be present $[9,10]$.

\section{Eradication of $H$. pylori and follow-up}

H. pylori infection was determined using a rapid urease test, a ${ }^{13}$ Curea breath test, and histology. For histological confirmation, two biopsy specimens were obtained from the greater curvature of the body, and the antrum and the specimens were examined after Giemsa staining. At least one positive result of the above tests was assumed as present $H$. pylori infection. If the patients showed positive results for $H$. pylori, eradication therapy was provided. As a first-line therapy, full-dose PPI, 500-mg clarithromycin, and 1000-mg amoxicillin, twice for 7-14 days, were prescribed. ${ }^{13}$ Curea breath test or rapid urease test was performed for confirming the success of eradication therapy after at least 4 weeks from the completion of eradication therapy. In the event that the patient failed triple therapy, bismuth-based quadruple therapy was initiated that consisted of full-dose PPI b.i.d., 500-mg metronidazole t.i.d., 500-mg tetracycline q.i.d., and 120-mg bismuth t.i.d. for 7-14 days. 
Full-dose PPI was usually prescribed for 4 weeks after endoscopic resection. Follow-up EGD was performed after 6 months for 2 years, and we evaluated the presence of $\mathrm{RE}$ and $H$. pylori status using the rapid urease test.

\section{Statistical analysis}

Continuous variables were reported as means \pm standard deviations. Depending on the distribution, the twosample t-test or the Mann-Whitney U test was used for comparing continuous variables. All $P$-values were twosided, and P-values of $<0.05$ were considered statistically significant. For analyzing the probability of RE and GERD symptoms, generalized estimating equation with logistic regression was used. Risk factors for RE and GERD symptoms were assessed using univariate and multivariate analyses with logistic regression analysis. All statistical analyses were performed using the statistical package for the social sciences software (SPSS version 21.0, Chicago, IL, USA).

\section{Results}

Study population

Of the 244 patients who were enrolled during the study period, 25 patients underwent surgery, 18 patients were lost to follow-up, and 28 patients who initially showed negative $H$. pylori results were excluded. Therefore, we analyzed the data of 173 patients who initially showed H. pylori-positive results. Baseline characteristics of this study population are presented in Table 1 . The percentage of males was found to be $76.9 \%$ and the mean age was 58 years. On final pathology of resected specimen, low-grade dysplasia was diagnosed in 61 cases (35.3\%), high-grade dysplasia in 18 cases (10.4\%), early gastric cancer in 92 cases (53.2\%), neuroendocrine tumor in one case $(0.6 \%)$, and gastritis in one case $(0.6 \%$; previous biopsy specimen was indicated as high-grade dysplasia, but final pathology did not show dysplastic lesions). Hiatal hernia was observed in $25 / 173$ cases $(14.5 \%)$. The prevalence of initial RE was $1.7 \%$ (3/173) and all the patients showed mild esophagitis, LA-A. The prevalence of initial GERD such as heart burn and acid regurgitation was $26.6 \%(46 / 173)$.

At 6,12, and 18-24 months after endoscopic resection, 173,159 , and 133 patients, respectively, were followed up. During the study period, 32 patients failed the first line eradication therapy, two patients refused for further eradication, and 30 patients underwent second line regimens. Among four patients who showed sustained positive result after the second line therapy, three underwent third line regimen (sequential therapy).

\section{Prevalence of RE and GERD symptoms}

There were $75.7 \%$ (131/173), 78.6\% (125/159), and 78.9\% $(105 / 133)$ subjects who were successfully eradicated after
Table 1 Baseline characteristics of the study population

\begin{tabular}{|c|c|}
\hline Variables & Total $(n=173)$ \\
\hline Number & 173 \\
\hline Male/female & $133 / 40$ \\
\hline Age & $58.0 \pm 8.0$ \\
\hline \multicolumn{2}{|l|}{ Body mass index } \\
\hline$<25$ & $103(59.5)$ \\
\hline $25-30$ & $63(36.4)$ \\
\hline $30-35$ & $6(3.5)$ \\
\hline$>35$ & $1(0.6)$ \\
\hline \multicolumn{2}{|l|}{ Past history } \\
\hline HTN & $47(27.2)$ \\
\hline $\mathrm{DM}$ & $25(14.5)$ \\
\hline Hyperlipidemia & $17(9.8)$ \\
\hline \multicolumn{2}{|c|}{ Final pathology of resected specimen } \\
\hline Low-grade dysplasia & $61(35.3)$ \\
\hline High-grade dysplasia & $18(10.4)$ \\
\hline Mucosal cancer & $89(51.4)$ \\
\hline Submucosal cancer & $3(1.7)$ \\
\hline Others & $2(1.2)$ \\
\hline \multicolumn{2}{|l|}{ Smoking } \\
\hline Current & $34(19.7)$ \\
\hline Past & $58(33.5)$ \\
\hline None & $81(46.8)$ \\
\hline \multicolumn{2}{|l|}{ Alcohol consumption } \\
\hline Current & $87(50.3)$ \\
\hline Past & $19(11.0)$ \\
\hline None & $67(38.7)$ \\
\hline Hiatal hernia & $25(14.5)$ \\
\hline \multicolumn{2}{|l|}{ Atrophic gastritis } \\
\hline None & $1(0.6)$ \\
\hline Open type & $132(76.3)$ \\
\hline Closed type & $40(23.1)$ \\
\hline Fasting glucose, mg/dL & $116.0 \pm 41.5$ \\
\hline Total cholesterol, mg/dL & $182.7 \pm 33.2$ \\
\hline \multicolumn{2}{|l|}{ Pepsinogen level } \\
\hline Pepsinogen I, ng/mL & $97.1 \pm 68.4$ \\
\hline Pepsinogen II, ng/mL & $18.4 \pm 10.7$ \\
\hline Pepsinogen $\mathrm{I} / \mathrm{II}$ ratio & $5.8 \pm 3.2$ \\
\hline
\end{tabular}

Values are presented with numbers (\%) and mean \pm standard deviation

6,12 , and 18-24 months, respectively. The prevalence of $\mathrm{RE}$ and GERD symptoms during follow-up period is presented in Table 2. The prevalence of RE and GERD symptoms between $H$. pylori-positive and $H$. pylori-negative patients is not significantly different at 6,12 , and 18-24 months after endoscopic resection. The probabilities of RE that failed to show a difference in both groups 
Table 2 Prevalence of reflux esophagitis and typical reflux symptoms after endoscopic resection

\begin{tabular}{lllll}
\hline Follow-up & & H. pylori-positive & H. pylori-negative & P-value \\
\hline 6 months & Reflux esophagitis & $5 / 28(17.9)$ & $18 / 127(14.2)$ & 0.569 \\
& Reflux symptoms & $6 / 27(22.2)$ & $24 / 129(18.6)$ & 0.664 \\
12 months & Reflux esophagitis & $4 / 18(22.2)$ & $21 / 116(18.1)$ & 0.745 \\
& Reflux symptoms & $2 / 17(11.8)$ & $26 / 111(23.4))$ & 0.360 \\
$18-24$ months & Reflux esophagitis & $2 / 12(16.7)$ & $18 / 10(17.1)$ & 1.000 \\
\hline
\end{tabular}

were as follows: 0.18 in $H$. pylori-positive vs. 0.14 in $H$. pylori-negative at 6 months, 0.22 vs. 0.18 at 12 months, and 0.17 vs. 0.17 at $18-24$ months after endoscopic resection, respectively $(P=0.95$, Fig. 1$)$. The probabilities of reflux symptoms that failed to show a difference in both groups were as follows: 0.22 in $H$. pylori-positive vs. 0.18 in $H$. pylori-negative at 6 months and 0.12 vs. 0.23 at 12 months, respectively $(P=0.18$, Fig. 2$)$.

\section{Factors associated with RE and GERD symptoms}

Univariate analysis for risk factors associated with RE is shown in Tables 3 and 4. Younger age (OR 3.71; 95\% CI, $P<0.012)$, present smoking status, alcohol consumption, and diabetes mellitus were associated with RE. In multivariate analysis, present smoking was noted to be the only significant risk factor for RE (Table 4).

In univariate analysis for factors associated with reflux symptoms, $H$. pylori infection had a positive association with male sex (OR 3.71; 95\% CI, 1.33-10.33, $P<0.012$ ). Otherwise, risk factors such as BMI and the presence of hiatal hernia were not associated with reflux symptoms.

\section{Discussion}

In the present study, we evaluated the probability of RE and reflux symptoms among patients with positive $H$. pylori who underwent endoscopic resection of gastric neoplasm. During the follow-up period, no significant difference was noted in the development for RE and reflux symptoms between $H$. pylori-positive and $H$. pylorinegative patients. We assumed that eradication therapy did not result in the development of RE or GERD symptoms.

It has been reported that $H$. pylori infection protects against the development of erosive esophagitis [11-14]. The first clinical trial suggested that the presence of $H$. pylori reduced the requirement of PPI [15]. In a study of patients with 244 duodenal ulcer, erosive esophagitis developed more frequently in patients treated with $H$. pylori eradication than that in $H$. pylori-positive patients [11]. However, more recent studies have suggested that $H$. pylori eradication does not have a clinical impact on RE. In a meta-analysis involving 11 randomized controlled trials, no difference in erosive esophagitis and reflux symptoms (reflux and heartburn) was noted between $H$. pylori eradication and persistent groups. In another meta-analysis including 10 trials, no statistically significant difference was found for endoscopic evidence of RE (OR 1.13; 95\% CI $0.72-1.78, p=0.59$ ) or symptomatic GERD (OR $0.81,95 \%$ CI $0.56-1.17, p=0.27$ ) between $H$. pylori treatment and the no-treatment groups

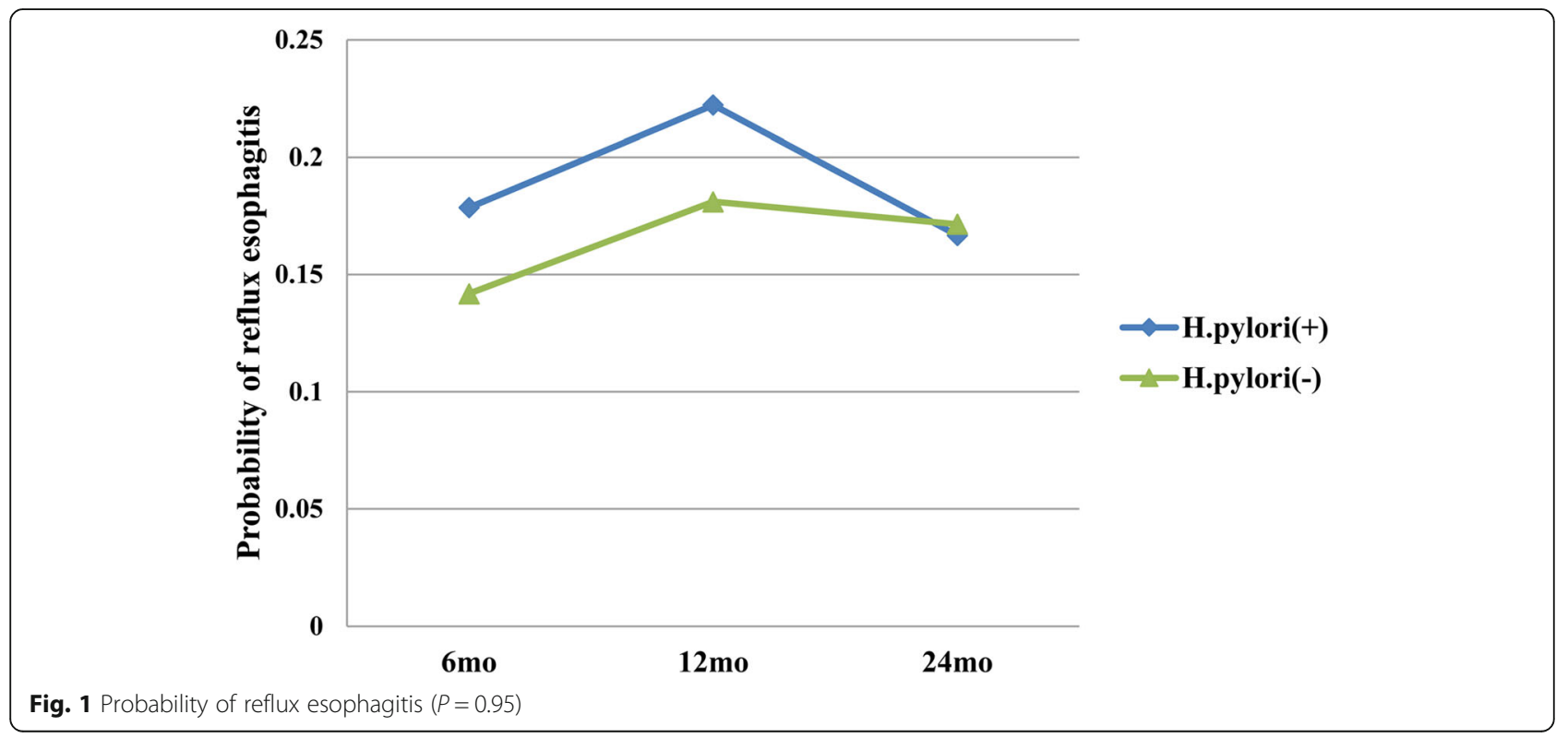




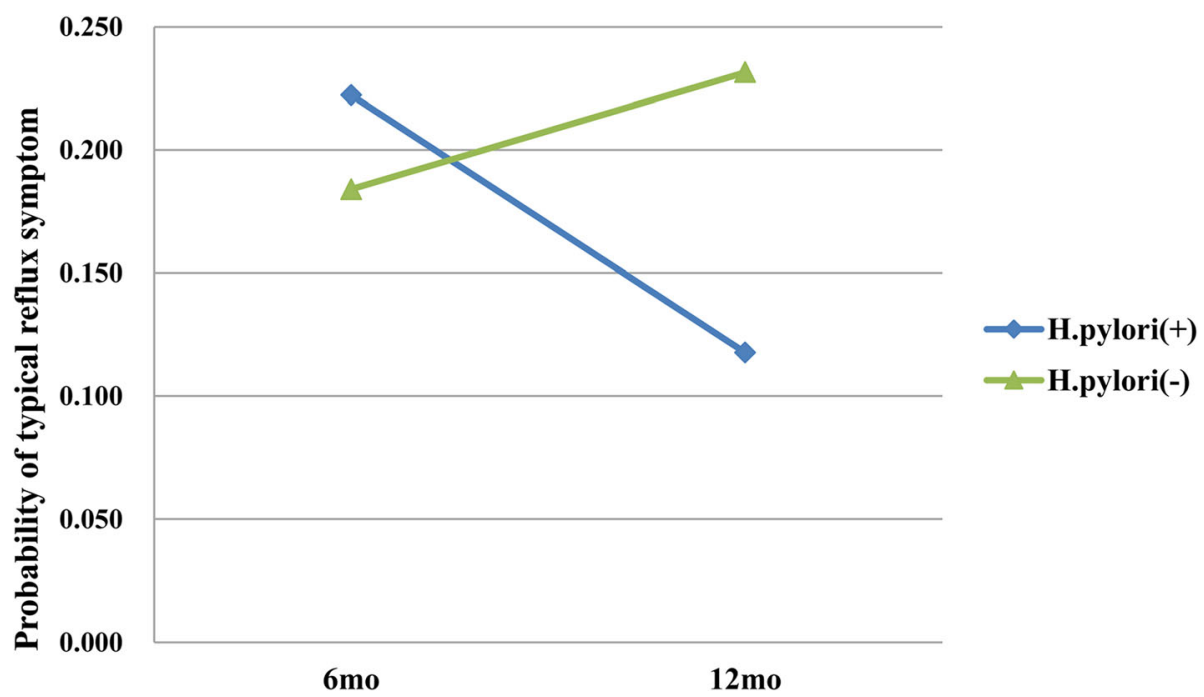

Fig. 2 Probability of reflux symptoms $(P=0.18)$

Table 3 Univariate analysis for risk factors of reflux esophagitis

\begin{tabular}{|c|c|c|c|c|c|c|c|}
\hline \multicolumn{2}{|l|}{ Risk factor } & \multirow{2}{*}{$\begin{array}{l}\text { Number } \\
133\end{array}$} & \multirow{2}{*}{$\begin{array}{l}\text { Event } \\
40\end{array}$} & \multirow{2}{*}{$\begin{array}{l}\text { Odds ratio } \\
2.028\end{array}$} & \multicolumn{2}{|c|}{$95 \% \mathrm{Cl}$} & \multirow{2}{*}{$\frac{P \text {-value }}{0.122}$} \\
\hline Sex & Male & & & & 0.828 & 4.967 & \\
\hline & Female & 40 & 7 & 1 & & & \\
\hline Age & & & & 0.956 & 0.917 & 0.996 & 0.032 \\
\hline \multirow[t]{3}{*}{ Body mass index } & $<25$ & 103 & 25 & 1 & & & 0.468 \\
\hline & $25-30$ & 63 & 19 & 1.347 & 0.668 & 2.718 & 0.405 \\
\hline & $>30$ & 7 & 3 & 2.340 & 0.490 & 11.599 & 0.286 \\
\hline \multirow[t]{3}{*}{ Smoking } & Present & 34 & 17 & 4.786 & 1.975 & 11.599 & 0.001 \\
\hline & Past & 58 & 16 & 1.823 & 0.807 & 4.116 & 0.148 \\
\hline & Non & 81 & 14 & 1 & & & 0.002 \\
\hline \multirow[t]{3}{*}{ Alcohol consumption } & Present & 87 & 30 & 2.186 & 1.033 & 4.627 & 0.041 \\
\hline & Past & 19 & 4 & 1.108 & 0.315 & 3.898 & 0.873 \\
\hline & Non & 67 & 13 & 1 & & & 0.090 \\
\hline \multirow[t]{2}{*}{ Hiatal hernia } & yes & 25 & 7 & 1 & & & \\
\hline & no & 148 & 40 & 1.050 & 0.408 & 2.703 & 0.919 \\
\hline \multirow[t]{2}{*}{ Hypertension } & no & 126 & 36 & 1 & & & \\
\hline & yes & 47 & 11 & 0.764 & 0.351 & 1.663 & 0.497 \\
\hline \multirow[t]{2}{*}{ Hypercholesterolemia } & no & 156 & 45 & 1 & & & \\
\hline & yes & 17 & 2 & 0.329 & 0.072 & 1.497 & 0.150 \\
\hline \multirow[t]{2}{*}{ Diabetes mellitus } & no & 148 & 36 & 1 & & & \\
\hline & yes & 25 & 11 & 2.444 & 1.020 & 5.861 & 0.045 \\
\hline Totalcholesterol & & 173 & & 1.007 & 0.997 & 1.017 & 0.188 \\
\hline Glucose & & 173 & & 1.005 & 0.998 & 1.013 & 0.189 \\
\hline
\end{tabular}


Table 4 Multivariate analysis for risk factor of reflux esophagitis

\begin{tabular}{llllll}
\hline Risk factor & & Odds ratio & $95 \% \mathrm{Cl}$ & & P-value \\
\hline Smoking & Present & 4.502 & 1.839 & 11.019 & 0.001 \\
& Past & 1.844 & 0.811 & 4.189 & 0.144 \\
& Non & 1 & & & \\
Diabetes mellitus & no & 1 & & & \\
& yes & 2.162 & 0.864 & 5.412 & 0.100 \\
\hline
\end{tabular}

[16]. A recent Japanese study that enrolled 8123 individuals for an annual checkup reported that the risk of RE in patients who underwent $H$. pylori eradication was even lower than those who were never infected [17].

GERD symptoms are relatively subjective and are not usually correlated with an endoscopic finding or a result from 24-h $\mathrm{pH}$ monitoring. Reports have demonstrated that $H$. pylori eradication does not lead to the development of GERD symptoms $[5,18]$. In a post-hoc analysis of eight double-blind prospective studies, $H$. pylori eradication did not result in the development of new symptomatic GERD or worsening of symptoms in patients with preexisting GERD [19].

Multiple pathophysiological factors influence the development and course of $\mathrm{RE}$, and gastric acid secretion is known to be a key factor in the pathophysiology of the disease. The possible underlying mechanism of $H$. pylori infection is associated with gastric acid output. In the early stage of the study, we postulated that our study population who primarily had severe atrophic gastritis and acid hyposecretion state would develop RE or GERD symptom after $H$. pylori eradication. Actually, many patients $(76.3 \%)$ showed open-type gastric atrophy and all patients except one showed atrophic changes. However, RE or GERD symptoms were not different between the two groups. In a prospective double-blind study measuring 24-h esophageal $\mathrm{pH}$ for established GERD patients, esophageal acid exposures were not different between $H$. pylori-positive and $H$. pylori-negative patients [20]. Another study evaluating 112 patients with GERD symptoms also showed that $H$. pylori infection did not affect esophageal acid exposure [21]. In patients with GERD without $H$. pylori infection, pathophysiological studies show that transient lower esophageal sphincter relaxations are the predominant mechanism of reflux [22].

In our study, smoking was the only risk factor for the development of RE. A recent study evaluated the risk factors for $\mathrm{RE}$ after the eradication of $H$. pylori; male sex, BMI $\geq 25 \mathrm{~kg} / \mathrm{m}^{2}$, the use of calcium channel blocker, and hiatal hernia were associated with the development of RE [23]. In another study evaluating the long-term effect of $H$. pylori eradication on the prevalence of RE, male sex, higher BMI, habitual alcohol consumption, habitual smoking, larger diaphragmatic hiatal size, and milder gastric mucosal atrophy were noted to be risk factors for RE [17].

Our study has several limitations. First, the prevalence of gastric atrophy was relatively higher in our study population and patients who have gastric neoplasm are not representative of the screened population. Second, the study was performed in a single center in Korea and ethnic variation could not be considered. Third, we did not perform functional study of gastroesophageal junction, which could have provided additional physiological evidence. Fourth, the questionnaire for GERD symptom evaluation was not validated. Despite these limitations, this is a prospective study that analyzes RE and GERD symptoms after $H$. pylori eradication among patients who underwent endoscopic resection of gastric neoplasm.

\section{Conclusions}

H. pylori eradication did not increase the incidence of endoscopic RE or typical GERD symptoms in patients who underwent endoscopic resection of gastric neoplasm.

\section{Supplementary information}

Supplementary information accompanies this paper at https://doi.org/10. 1186/s12876-020-01276-1.

\section{Additional file 1.}

\section{Abbreviations}

GERD: Gastroesophageal reflux disease; RE: Reflux esophagitis;

H.pylori: Helicobacter pylori; OR: Odd ratio; Cl: Confidential interval; BMI: Body mass index; PPI: Proton pump inhibitor; PG: Pepsinogen

\section{Acknowledgments}

The authors confirm that there are no financial arrangements with anyone.

\section{Authors' contributions}

$\mathrm{LJH}$ designed the study and recruited the patients; NHK performed the procedure and analyzed the data; NHK and LJH wrote the manuscript; NHK, PSJ and PHJ reviewed medical records and collected data. KSO reviewed the statistical data. AJY, KDH, JKW, CKD, SHJ, LGH, and JHY supervised the study. All authors were involved in critical revision of the paper. The author(s) read and approved the final manuscript.

Funding

The authors declare that no funding was received for the present study.

\section{Availability of data and materials}

The datasets used and/or analyzed during the present study are available from the corresponding author on reasonable request.

\section{Ethics approval and consent to participate}

Written consent was obtained from each patient in advance. The study was conducted according to the guidelines of the Declaration of Helsinki and was approved by the Institutional Review of Board of Asan Medical Center (IRB number: 2014-2-10).

Consent for publication

Not applicable.

Competing interests

The authors declare that they have no competing interests. 


\section{Author details}

'Department of Gastroenterology, University of Ulsan College of Medicine, Asan Medical Center, 88, Olympic-ro 43-gil, Songpa-gu, Seoul 05505, South Korea. ${ }^{2}$ Department of Clinical Epidemiology and Biostatistics, University of Ulsan College of Medicine, Asan Medical Center, 88, Olympic-ro 43-gil, Songpa-gu, Seoul 05505, South Korea.

Received: 4 March 2020 Accepted: 15 April 2020

Published online: 21 April 2020

\section{References}

1. Schutze K, Hentschel E, Dragosics B, Hirschl AM. Helicobacter pylori reinfection with identical organisms: transmission by the patients' spouses. Gut. 1995;36:831-3.

2. Fallone CA, Barkun AN, Friedman G, Mayrand S, Loo V, Beech R, et al. Is helicobacter pylori eradication associated with gastroesophageal reflux disease? Am J Gastroenterol. 2000;95:914-20.

3. Cremonini F, Di Caro S, Delgado-Aros S, Sepulveda A, Gasbarrini G, Gasbarrini A, et al. Meta-analysis: the relationship between helicobacter pylori infection and gastro-oesophageal reflux disease. Aliment Pharmacol Ther. 2003;18:279-89.

4. Wang Z, Shaheen NJ, Whiteman DC, Anderson LA, Vaughan TL, Corley DA et al. Helicobacter pylori infection is associated with reduced risk of Barrett's esophagus: an analysis of the Barrett's and esophageal adenocarcinoma consortium. Am J Gastroenterol. 2018;113:1148-55.

5. Kandulski A, Malfertheiner P. Helicobacter pylori and gastroesophageal reflux disease. Curr Opin Gastroenterol. 2014;30:402-7.

6. Armstrong D, Bennett JR, Blum AL, Dent J, De Dombal FT, Galmiche JP, et al. The endoscopic assessment of esophagitis: a progress report on observer agreement. Gastroenterology. 1996;111:85-92.

7. Hamada H, Haruma K, Mihara M, Kamada T, Yoshihara M, Sumii K, et al. High incidence of reflux oesophagitis after eradication therapy for helicobacter pylori: impacts of hiatal hernia and corpus gastritis. Aliment Pharmacol Ther. 2000;14:729-35.

8. Ahn SY, Lee SY, Hong SN, Kim JH, Sung IK, Park HS, et al. Endoscopic diagnosis of open-type atrophic gastritis is related to the histological diagnosis of intestinal metaplasia and Cdx2 expression. Dig Dis Sci. 2011;56: 1119-26.

9. Varis K, Sipponen P, Laxen F, Samloff IM, Huttunen JK, Taylor PR, et al. Implications of serum pepsinogen I in early endoscopic diagnosis of gastric cancer and dysplasia. Scand J Gastroenterol. 2000;35:950-6.

10. Sipponen P, Graham DY. Importance of atrophic gastritis in diagnostics and prevention of gastric cancer: application of plasma biomarkers. Scand J Gastroenterol. 2007:42:2-10.

11. Labenz J, Blum AL, Bayerdorffer E, Meining A, Stolte M, Borsch G. Curing helicobacter pylori infection in patients with duodenal ulcer may provoke reflux esophagitis. Gastroenterology. 1997;112:1442-7.

12. Malfertheiner P, Megraud F, O'Morain CA, Atherton J, Axon AT, Bazzoli F, et al. Management of Helicobacter pylori infection--the Maastricht IV/ Florence consensus report. Gut. 2012;61:646-64.

13. Lee JM, O'Morain CA. Different management for helicobacter pylori positive and negative patients with gastro-oesophageal reflux disease? Gut. 1998; 43(Suppl 1):S14-20.

14. Sacca N, De Medici A, Rodino S, De Siena M, Giglio A. Reflux esophagitis: a complication of helicobacter pylori eradication therapy? Endoscopy. 1997; $29 \cdot 224$

15. Hallerback B, Unge P, Carling L, Edwin B, Glise H, Havu N, et al. Omeprazole or ranitidine in long-term treatment of reflux esophagitis. Gastroenterology. 1994;107:1305-11.

16. Saad AM, Choudhary A, Bechtold ML. Effect of helicobacter pylori treatment on gastroesophageal reflux disease (GERD): meta-analysis of randomized controlled trials. Scand J Gastroenterol. 2012;47:129-35.

17. Adachi K, Notsu T, Mishiro T, Kinoshita Y. Long-term effect of helicobacter pylori eradication on prevalence of reflux esophagitis. J Gastroenterol Hepatol. 2019:34:1963-7.

18. Xinias I, Maris T, Mavroudi A, Panteliadis C, Vandenplas Y. Helicobacter pylori infection has no impact on manometric and $\mathrm{pH}$-metric findings in adolescents and young adults with gastroesophageal reflux and antral gastritis: eradication results to no significant clinical improvement. Pediatr Rep. 2013;5:e3
19. Laine L, Sugg J. Effect of helicobacter pylori eradication on development of erosive esophagitis and gastroesophageal reflux disease symptoms: a post hoc analysis of eight double blind prospective studies. Am J Gastroenterol. 2002:97:2992-7.

20. Fallone CA, Barkun AN, Mayrand S, Wakil G, Friedman G, Szilagyi A, et al. There is no difference in the disease severity of gastro-oesophageal reflux disease between patients infected and not infected with helicobacter pylori. Aliment Pharmacol Ther. 2004;20:761-8.

21. Zentilin $P$, liritano $E$, Vignale $C$, Bilardi $C$, Mele MR, Spaggiari $P$, et al. Helicobacter pylori infection is not involved in the pathogenesis of either erosive or non-erosive gastro-oesophageal reflux disease. Aliment Pharmacol Ther. 2003;17:1057-64.

22. Yucel O. Interactions between helicobacter pylori and gastroesophageal reflux disease. Esophagus. 2019;16:52-62.

23. Harada A, Kurahara K, Moriyama T, Tanaka T, Nagata Y, Kawasaki K, et al. Risk factors for reflux esophagitis after eradication of helicobacter pylori. Scand $J$ Gastroenterol. 2019;54:1183-8.

\section{Publisher's Note}

Springer Nature remains neutral with regard to jurisdictional claims in published maps and institutional affiliations.

Ready to submit your research? Choose BMC and benefit from:

- fast, convenient online submission

- thorough peer review by experienced researchers in your field

- rapid publication on acceptance

- support for research data, including large and complex data types

- gold Open Access which fosters wider collaboration and increased citations

- maximum visibility for your research: over $100 \mathrm{M}$ website views per year

At BMC, research is always in progress.

Learn more biomedcentral.com/submission 